

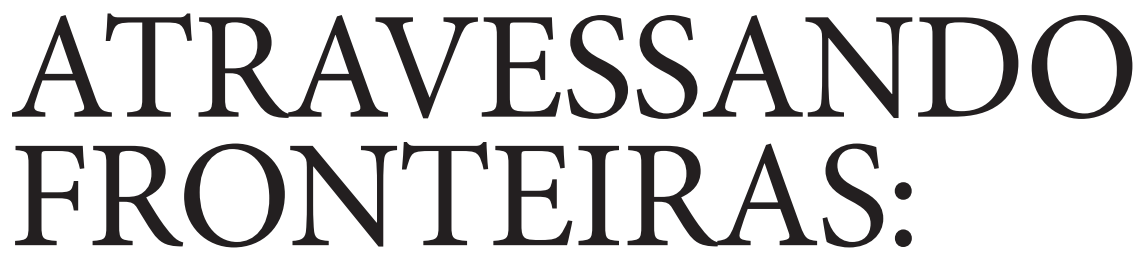

\section{uma releitura da Antropologia da Arte proposta por Alfred Gell a partir de um Ibiri de Mestre Didi}

\section{HELIO MENEZES*}

RESU Mo Com base no exercício de observação de uma obra de arte de Mestre Didi - Ibiri, emblema do orixá Nanã -, proponho uma revisita às principais contribuições de Alfred Gell para uma análise de tipo antropológico do objeto artístico, indiciando os aportes e limites de sua abordagem à constituição dessa subárea disciplinar, tão instável quanto de difícil demarcação, convencionalmente denominada "Antropologia da Arte".

palavras-chave Antropologia da arte. Alfred Gell. Mestre Didi.

\section{CROSSING BOUNDARIES:}

\section{a rereading of the Anthropology of Art proposed by Alfred Gell from an Ibiri by Mestre Didi}

ABSTRACT Observing a work of art by Mestre Didi called Ibiri, the emblem of the Nanã orixa, Alfred Gell's major contributions to an anthropological analysis of the artistic object are revisited, indicating collaborations and limits of his approach to the formation of the disciplinary subfield - as unstable as difficult to limit - conventionally known as "Anthropology of Art".

KEYwords Anthropology of art. Alfred Gell. Mestre Didi..

* Mestrando no Programa de Pós-graduação em Antropologia Social da Universidade de São Paulo (PPGAS-USP).

E-mail: heliosmenezes@gmail.com

Recebido em 8/8/2015. Aprovado em 21/3/2016 


\section{Introdução: abrindo caminhos}

ste ensaio caminha num terreno lodoso entre duas fronteiras, ambas po-
rosas, e nas sendas de dois célebres intermediários-guias: entre o Orun e o Aiүê e entre a Antropologia e a Arte, inspirado na criatividade e argúcia analítica de Mestre Didi e Alfred Gell. Por meio do exercício de observação de uma obra de arte do primeiro - Ibiri, emblema do orixá Nanã (imagem oI) -, proponho uma revisita às principais contribuições do segundo, para uma análise de tipo antropológico do objeto artístico, indiciando os aportes e limites de sua abordagem à constituição dessa subárea disciplinar, tão instável quanto de difícil demarcação, convencionalmente denominada "Antropologia da Arte”. Não pretendo, destarte, buscar resolver as intricadas querelas desse campo, tampouco reduzir a enorme e complicada obra desses dois autores a uma porção de juízos de maior ou menor envergadura ensaística. Limito-me aqui - e como hipótese - a pensar, considerando alguns dos temas que entrecruzam tais fronteiras e destacando seus pontos de contato e tensão.

O desafio é dos maiores. Os albores da história da Antropologia, como se sabe (Clifford, I988; Stocking Jr., I985), estiveram intimamente ligados à história do colecionismo ocidental (ou saque colonial, para usarmos de um léxico mais claro) das coisas dos Outros. As numerosas exposições universais (Stocking Jr., I987) e os gabinetes de curiosidade das cortes europeias, com seus conjuntos heteróclitos de coisas ditas exóticas (modernamente repaginados como museus etnográficos), expõem tal imbricação em seu paroxismo. Tal história, entretanto, e contrariamente às premissas de progressão unilinear e evolutiva do ambiente vitoriano de emergência da Antropologia como disciplina, é marcada por inflexões e desvios de curso, como as múltiplas contribuições de variados antropólogos à compreensão das artes. 


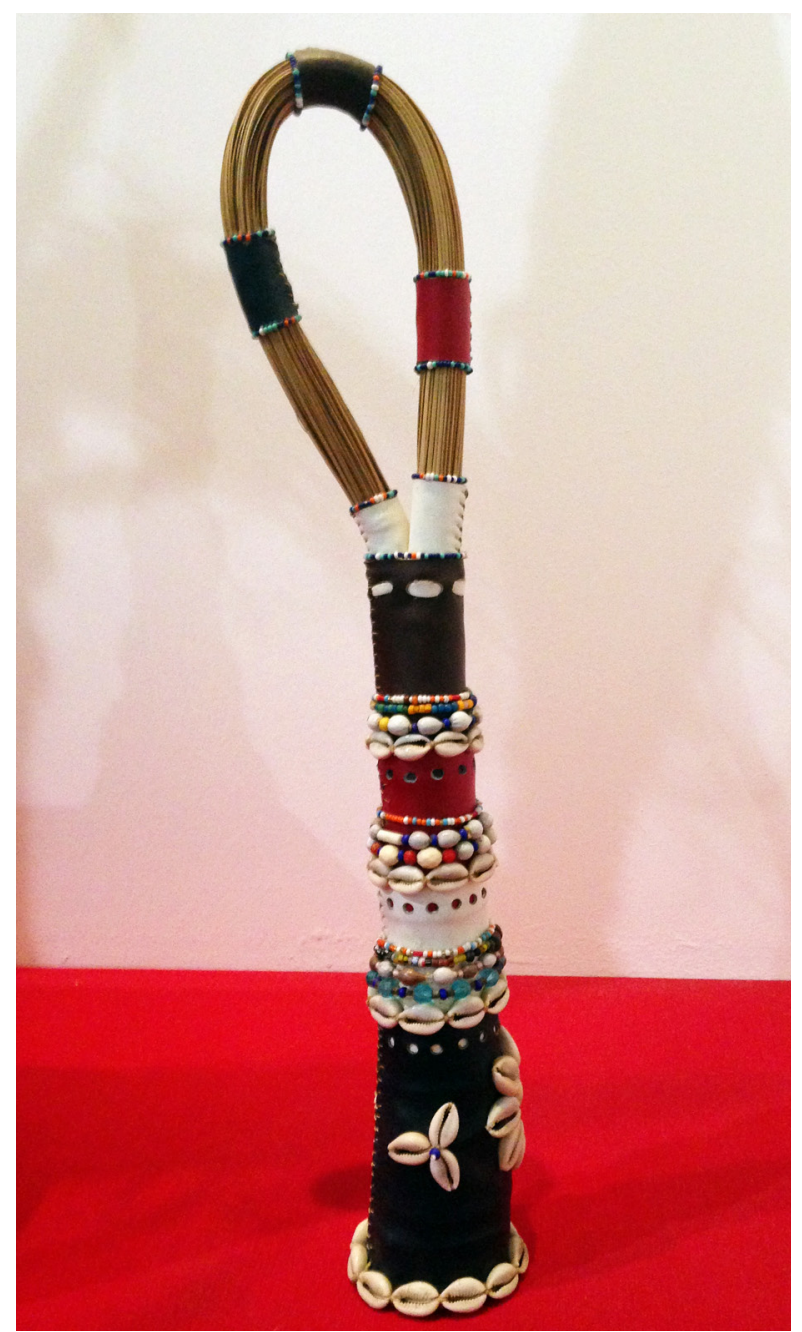

Imagem 1 Mestre Didi. Ibiri - Emblema do Orixá Nanã. S.d.Fibra vegetal, búzio, miçangas e couro. 52,5 × 13,8 x 8cm. Acervo Museu Afro-Brasil. Fotografia do próprio autor do ensaio

A incorporação de objetos "artísticos" como matéria de interesse antropológico de produção, estão presentes desde os textos inaugurais da Antropologia: é largamente conhecido o enunciado que abre o livro de E. B. Tylor, Cultura primitiva, de I87I, no qual a "cultura, ou civilização, tomada em seu mais amplo sentido etnográfico" é definida como "aquele todo complexo que inclui conhecimento, crença, arte, moral, lei, costume e quaisquer outras capacidades e hábitos adquiridos pelo melhor - se faz impositivo para demarcar que, embora em voga, o conceito de "objeto artístico" está longe de ser unívoco, e seu uso, não raras vezes, pode esbarrar em imprecisões. Nesse sentido, Clifford relembra, com razão, que a "arte não é universal, homem na condição de membro da sociedade" (Tylor apud Castro, 2005, p. 69. O grifo é meu). Tais noções de “cultura”, “civilização” e “sociedade” serão ulteriormen- 
te objeto de profundo questionamento (Strathern, I988; Gell, I998; Wagner, 20I0, entre outro) e, tal como "arte” ou “estética”, de difícil acepção consensual no interior da disciplina (cf. Coote, I992; Morphy, I994 e, especialmente, Ingold, I994).

Não obstante, parece subjazer à supradita multiplicidade de (re)definições antropológicas da noção de arte uma característica que a elas é mais ou menos comum e que as diferencia das aproximações mais claramente históricas, filosóficas e/ou sociológicas ao tema. Se M. Sahlins tem razão ao postular que “toda coisa pode ser conhecida por suas relações com um número indefinido de outras coisas; donde, a objetividade do objeto é sempre seletiva" (Sahlins, 2004, p. 54), então o campo das artes, com efeito, apresenta-se como terreno fértil ao pensamento antropológico, sobretudo naquilo que aparece como sinal diacrítico dessa disciplina, isto é, a recusa em reconhecer propriedades imanentes a qualquer objeto ou signo, a impertinência da ontologização de objetos com base em uma definição a priori da coisa-em-si, e a defesa de um olhar que realça a constituição dos processos sociais de significação das coisas-em-relação. Em outras palavras, um pensamento que opera pela recuperação dos sentidos imputados aos objetos por aqueles com os quais, e por meio dos quais, eles se relacionam num dado tempo e espaço, reinserindo-os nos sistemas classificatórios em que estiveram (ou estão) socialmente subsumidos.

Gell, ainda que hesite em reconhecer e nomear as contribuições dos antropólogos que o antecederam no estudo da arte (com algumas ideias inclusive não muito distantes das suas, como destaca R. Layton, 2003, passim), é certamente tributário desse tipo de olhar caro à Antropologia. Não obstante, a originalidade de algumas de suas proposições, como a procura em responder a uma obra de arte como se esta fosse "um ser copresente, um pensamento encarnado" (Gell, 200I, p. I83), ou o alargamento da noção de objeto artístico a virtualmente qualquer coisa, fazendo implodir a cediça distinção entre arte e artefato, é inegável.

É na fecundidade desse pensamento e questionando a recusa seletiva de A. Gell ao valor que a abordagem semiótica pode ter frente ao objeto artístico (ou, melhor dizendo, pondo à prova o diminuto e intermitente, mas não necessariamente ausente, recurso a tal abordagem em suas considerações, como tentarei demonstrar) que busco analisar o supramencionado Ibiri esculpido por Mestre Didi, a um só tempo arte $e$ artefato. Uma peça que embaralha e torna a ideia de objeto trickster - "um objeto 
etnográfico e um objeto artístico [que] aparecem como as duas faces conjuntas de uma realidade cultural", nas palavras de T. Dufrêne (20I2, p. II8) - ainda mais complicada (se não analiticamente imprecisa, pelo uso pouco cuidadoso da noção, um tanto cediça e tendenciosamente reificante, de "realidade cultural").

Destarte, procuro associar à inovadora ênfase de Gell à capacidade agentiva das coisas, os ensinamentos deixados por M. Mauss de que "todo objeto deve ser estudado: $1^{\circ}$ em relação a si mesmo; $2^{\circ}$ em relação às pessoas que se servem dele; $3^{\circ} \mathrm{em}$ relação à totalidade do sistema observado" (Mauss, I993, p. 47.).

\section{Partindo (d)o concreto: o ibiri de Nanã e o Ibiri ${ }^{2}$ de Didi}

Filho biológico de Mãe Senhora, renomada ialorixá do Ilê Axé Opô Afonjá, o sacerdote-artista Mestre Didi (I9I7-20I3) nasceu na cidade do Salvador (BA) sob o nome de Deoscóredes Maximiliano dos Santos. Iniciado, ainda garoto, nesse mesmo candomblé de linha Ketu, recebeu o título de Assògbá, sumo sacerdote do culto aos orixás telúricos - Nanã, Oxumarê e Obaluayê - pelas mãos de Mãe Aninha, fundadora do referido terreiro. Devido a tal designação, eram suas as tarefas de execução e sacralização das ferramentas e insígnias rituais dedicadas a esses orixás. Foi também Alapini, o mais alto grau do culto aos ancestrais Egunguns, do Ilê Axé Asipá, terreiro por ele fundado em I980, também na Bahia.

A qualidade peculiar de suas obras de arte - ou, melhor dizendo, de suas obras deliberadamente confeccionadas para os circuitos expositivos e de mercado da arte foi logo reconhecida e mundialmente aclamada. Participou de inúmeras exposições individuais e coletivas, do Museu de Arte Moderna da Bahia (Salvador, I996) ao Schomburg Center (Nova York, I986), além do Palácio da UNESCO e da afamada (e controversa) Magiciens de la Terre, no Centre Georges Pompidou (Paris, I970 e I989, respectivamente), entre outras. O conjunto de sua obra consiste basicamente de esculturas relacionadas aos orixás e demais entidades do panteão afro-brasileiro.

2 Ao longo do texto, uso “ibiri”, em minúscula, para referir-me aos ibiris de um modo geral, em contraposição a Ibiri, com inicial maiúscula e em itálico, grafia com a qual me refiro especificamente à obra de Mestre Didi em questão. "Ibiri", com inicial maiúscula, refere-se às situações que dizem respeito a ambos. 
Diferentemente das representações artísticas mais conhecidas desses deuses, claramente antropomórficas (como as famosas aquarelas de Carybé - imagem 02), as esculturas verticalizadas de Mestre Didi, em estreita ligação com a tradição filosóficoreligiosa relacionada às divindades de origem iorubana, cuja natureza prescinde de formas materiais de apresentação, referem-se aos orixás de maneira alusiva e metafórica, por meio de seus mitos, cores e insígnias. É esse o caso do Ibiri, sobre o qual nos debruçaremos nas páginas seguintes.

A literatura dedicada a Mestre Didi é relativamente curta. À parte alguns textos em catálogos de exposições, materiais jornalísticos e de críticos de arte, são os escritos da antropóloga Juana Elbein dos Santos (1996; I997; 2007; entre outros), também sua cônjuge em vida, o corpus mais consistente de análise de suas obras. Dona de um

3 Parte de minhas considerações neste breve ensaio, como se fará notar, é também, e confessadamente, devedora de sua instigante análise. olhar sagaz e minucioso, além de profundamente familiarizada com o universo religioso afro-baiano e privilegiada pela enorme proximidade que tinha com seu sujeito de estudo, Santos é referência incontornável ${ }^{3}$ a quem se dedica a pensar as obras de Deoscóredes e seu processo criativo, sobre o qual nos diz:

Cada manifestação cultural se expressa simultaneamente através de conteúdos aparentes, abertos, visíveis, ou manifestos em um nível consciente e de conteúdos latentes, ocultos ou reprimidos no nível inconsciente. A religião, a mitologia e a arte são os veículos mais sensíveis através dos quais uma cultura manifesta seus conteúdos e necessidades latentes. O místico e o artista são iniciados que aprendem a manejar seu especial aparato sensitivo que lhes permitirá ser os coletores mais receptivos e originais de uma comunidade. Ao resumir suas experiências e inquietudes nas "obras-símbolos" criam os "microcosmos" de todo um sistema cultural (Santos, I996, n.p.).

Sua abordagem, bastante preocupada com a capacidade de comunicação simbólica das obras e de clara inspiração semiótico-iconográfica, entretanto, parece-me pouco aberta às ideias de "agência, intenção, causação, resultado e transformação" de que fala Gell (I998, p. 6) sobre o objeto artístico. Parece-me também impreterível submetê-la a uma espécie de profanação da obra de arte, historicizando-a, retirando-a do reino dos deuses para, como o fez Prometeu com o fogo, reinseri-la no reino dos homens. Ou seja, do exercício permanente de questionamento da leitura, um tanto romântica e romanceada, de uma suposta aura mágica e demiúrgica do artista e de sua obra. Como afirma LéviStrauss, a respeito da produção artística e seus arroubos de singularidade, "pretendendose solitário, o artista alimenta uma ilusão talvez fecunda, mas o privilégio que se arroga 


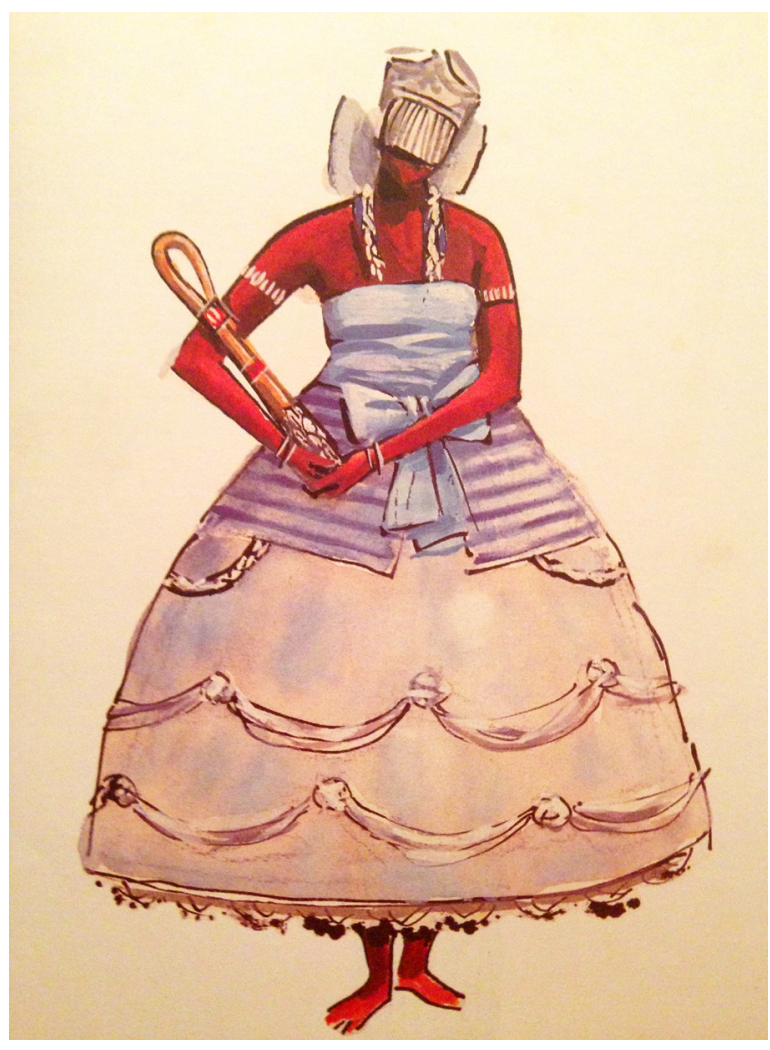

Imagem 2 Carybé. Nanã Burukú. Olga do Alaketu (ao centro) e Ferramenta de Nanã Burukú - o Ibiri (à direita). S.d.

Fonte: CARYBÉ. 1980. Iconografia dos deuses africanos no candomblé da Bahia. São Paulo: Raízes, p. 107-108. nada tem de real. Quando julga exprimir-se de uma forma espontânea e fazer obra original, está a repetir outros criadores, passados ou presentes, reais ou virtuais. Saiba-se ou não, nunca se caminha sozinho pelas veredas da criação" (Lévi-Strauss, I979, p. I28).

Nos termos de nossa análise, tal afirmação se revela especialmente pertinente pela necessidade em atentar-nos aos diálogos "internos" que as obras de arte do universo religioso afro-brasileiro praticam entre si, seja em relação às obras predecessoras do próprio artista $^{4}$ ou de outrem, num exercício contínuo e imbricado de comunicação e influências recíprocas 5 , o que implica não perder de vista a intertextualidade latente que liga a peça de Mestre Didi aos demais ibiris que o precederam. Em outras palavras, trata-se de ajustar o olhar para uma perspectiva atenta aos "modos pelos quais", como diz B. Latour, "a cascata de imagens é discernível no domínio artístico - a firme e intricada conexão que cada imagem tem com todas as outras que foram produzidas, a complexa relação de sequestro, alusão, destruição, distância, citação, paródia e disputa" (Latour, 2008, p. I4I). Não à toa, como veremos, os traços estilísticos fundamentais do Ibiri já estavam há muito sedimentados. A criatividade de Mestre Didi, contudo, tratará de singularizá-lo frente aos seus homólogos menos célebres.

Espécie de cetro encurvado em uma de suas extremidades e embalado pelas filhasde-santo incorporadas por Nanã, o ibiri é a insígnia mais importante desse orixá. Conta um de seus mitos que o foi apontando para o fundo de um lago que essa antiga divindade, senhora dos pântanos e regiões lodosas, teria indicado a lama com a qual Oxalá,
4 Mestre Didi elaborou uma série de variações de Ibiris, bastante similares entre si, ainda que únicos. Neste ensaio, atenho-me a apenas um deles.

5 Algo próximo ao que Gell chama de "estilo" (1998, especialmente capítulo 8 - "Style and Culture"), excetuando-se a tendência reificante de "cultura" com que esse termo flerta em sua acepção, sobretudo ao desconsiderar as enormes diferenças "estéticas" oriundas de distintas oficinas de produção (olarias, cestarias corporações de ofício etc.) no interior de uma mesma "cultura". Além da sua completa opacidade de sentido em relação ao que se pode entender de um "estilo" eminentemente individual, como a de um Picasso ou um Mestre Didi. 
entidade então encarregada por Olorum (literalmente, “Dono do Céu”, em iorubá) a dar forma ao mundo, deveria modelar o ser humano (Prandi, 200I, p. I96). Chamado ileeshin nos cultos iorubanos na África (mais especificamente, em parte do território dos atuais Nigéria, Benin e Togo), em sua base podem ser incrustadas poderosas substâncias medicinais, transformando-o numa verdadeira arma de cura/descura.

Personagem fundamental do começo do mundo, Nanã é associada à própria Terra. É lama, terra molhada, matéria-prima da vida e à qual todos retornam em forma de pó, segundo a cosmogonia nagô (Santos, I976). IYa-nlá, a “Grande Mãe Terra” iorubana, de onde brotam florestas e por onde percorrem rios e mares - elementos e domínios prescritos a uma vasta série de orixás - é fonte de axé, de vida e de morte, morada dos deuses e lócus privilegiado do sagrado afro-brasileiro. Espécie de oposto especular do elevado e celeste Olimpo grego, é em direção à Terra que os iniciados curvam suas cabeças e prostram seus corpos, em reverência a seus deuses. O manejo de seus elementos e, com mais razão, dos objetos a ela associados, requer cuidado.

No interior das casas de culto afro-brasileiro, a confecção dos ibiris é tarefa exclusiva dos sacerdotes de alta hierarquia, devidamente treinados nos ritos que ordenam a manipulação de objetos tão perigosos. Mestre Didi, a um só tempo artista e sacerdote, não só podia como devia confeccioná-los. E, ao fazê-los seguindo à risca os preceitos religiosos, incutia-lhes também uma clara intencionalidade artística, implodindo os limites entre arte e artefato, entre objeto de arte e objeto funcional. No caso de seu Ibiri, a asserção gelliana de que "a separação entre instrumentalidade e espiritualidade é impraticável” (Gell, 200I, I8I) ganha contornos superlativos. Tornando ainda mais instigante a sua indagação: "se as obras de arte são um tipo de instrumento (o que, creio eu, não seria questionado pelos escultores africanos [ou afro-brasileiros, adicionaríamos]), por que não considerar também que os instrumentos podem ser um tipo de obra de arte?" (ibidem).

Utilizando-se de miçangas, búzios (ou cauris), fibra vegetal e couro - elementos naturais mitologicamente ligados ao culto de Nanã -, Mestre Didi elabora Ibiris altamente estilizados, em cujo formato uterino se deixa transparecer os domínios de ancestralidade e fecundidade cosmologicamente atribuídos a esse orixá, evidenciando seu aspecto maternal, presente tanto em seu próprio nome (“Na”, raiz proto-sudânica ocidental, significa “mãe”, como ensina Santos, ı996, n.p.) quanto, como vimos, na 
sua relação com a lama. Os mortos que ela recebe no fundo de seus pântanos são parte insolúvel do ciclo da vida; são, nesse sentido, seus filhos tanto como o são os vivos. Com efeito, as nervuras de palmas de palmeiras que dão corpo aos ibiris são símbolo dos eguns (ancestrais) e dos oku-orun (falecidos), igualmente representados nos cauris (exoesqueleto dos moluscos que neles antes habitavam) que adornam o Ibiri e funcionam como metáfora do corpo-sem-corpo, ou "doble espiritual” (op. cit., ibidem) dos antepassados cultuados nos terreiros de Egunguns. O mesmo se poderia inferir dos efeitos de preenchimento e vazamento do espaço escultórico do Ibiri, em que presente e ausente, positivo e negativo, se conformam para formar um todo.

O branco, vermelho, preto e índigo, cores que Mestre Didi emprega em seu Ibiri, seguindo rigorosamente a simbologia desses pigmentos no universo religioso Ketu, são também densamente alegóricos. "A cor índigo escuro - axé do preto", ensina Santos (2007, p. 66), “está associada com a terra e o mistério de transformação da morte em vida. O branco - axé do branco - está associado ao princípio gerador masculino da existência, e a cor vermelha - axé do vermelho - apresenta a fertilidade, o poder gerador feminino". Trata-se, claro está, de convenções religiosas, trasladadas pela engenhosidade de Mestre Didi em convenções também artísticas, igualmente presentes em obras de variados artistas que se dedica(ra)m à arte afro-brasileira de inspiração religiosa (e.g. Djanira da Mota e Silva, Ronaldo Rêgo e Rubem Valentim).

\section{Especulando o abstrato: a decomposição do Ibiri}

A noção de convenção aqui empregada exige que nos detenhamos com maior minudência sobre seu significado, à luz das considerações que Gell lhe dedica em suas análises sobre a visualidade de ídolos e fetiches (I998, mais especificamente nos capítulos 4 - “The Involution of Index” e 7 - “The Distributed Person”). De início, é preciso sublinhar que me parece inteiramente impreciso qualificar o Ibiri (objeto não sacralizado), ou mesmo um ibiri que tenha passado pelos ritos de sacralização e transferência de faculdades místicas, como um ídolo ou fetiche. Não se lhes presta culto como se estes fossem Nanã, aos moldes da "imagem viva” de Jagganah em Puri (Gell, I998, pp. I44-8); tampouco se lhes atribui poderes mágicos per se, isolados do seu uso ritual por indivíduos específicos em situações rigorosamente prescritas, às feições de 
uma Nkisi congolesa (op. cit., pp. 59-62). Embora a sugestão gelliana de que "ídolos não são descrições, nem retratos, mas corpos manufaturados (op. cit., p. 98. O grifo é original.) seja inteiramente extensível aos Ibiris.

O Ibiri não é um objeto-divindade. Trata-se, mais propriamente, de um emblema, a dizer, um "ser, objeto ou signo convencional que simboliza uma ideia abstrata, uma coletividade, uma autoridade". Uma representação material que "funciona porque tem ressonâncias iconográficas e históricas complexas (dantoescas), das quais o público de galeria está, em maior ou menor extensão, ciente [...], que evoca ou significa algo interessante, difícil, alusivo, complicado de realizar" (Gell, 200ı, p. I89. Os grifos, meus, visam destacar o avizinhamento do linguajar empregado por Gell à terminologia típica da abordagem semiótica por ele tão duramente criticada). Um símbolo sinedóquico, por assim dizer, a um só tempo icônico (na medida em que se trata de uma representação metafórica) e anicônico (em face à prescindibilidade de apresentação material dos deuses iorubanos, como sobredito) de Nanã, seu protótipo (os termos destacados são do léxico de Gell, I998).

O afastamento de Gell de uma abordagem antropológica da arte alicerçada na decifração de convenções simbólicas, coerentemente com sua crítica à aproximação iconográfica levada a cabo por Panofsky (Gell, 2005), é contundente: “não acredito que representação icônica se baseie em ‘convenção’ simbólica (comparável a 'convenções' que estabelecem que ‘dog' signifique ‘canine’ em Inglês)” (Gell, I998, p. 25). Tal postura, entretanto, parece-me mais aparente que real. Ou, melhor dizendo, mais intermitente que radical. É esse mesmo autor quem nos diz, páginas adiantes, que “todos os ídolos, creio, são 'icônicos' - inclusive os ditos anicônicos - pareçam eles ou não a algum objeto familiar, como um corpo humano” (op. cit., p. 97), e continua, afirmando que "uma vez que um ídolo é um artefato (e não um objeto natural, como uma pedra meteórica), a natureza da agência exercida pelo protótipo é o que motiva o artista a produzir uma imagem religiosamente estipulada [como o ibiri?] em conformidade às convenções para tais imagens, que podem ser icônicas/antropomórficas ou abstratas e anicônicas” (op. cit., p. 99. O grifo é meu.).

E já que falávamos há pouco das cores do Ibiri como convenções artísticas que veiculam significados simbólicos, valeria relembrar a conhecida (e valiosa) crítica de Gell (I995) aos limites da noção de estética empregada por Jeremy Coote (I992). Ao advo- 
gar pela indissociabilidade entre razões estéticas (como a de "beleza”) e razões práticas (como a de auferir "prestígio"), Gell descarta o entendimento da estética como um "modo de ver", decorrente da suposta recepção e processamento do mundo objetivo por aparelhos sensoriais universais de percepção e cognição, uma espécie de sensibilidade prévia aos trabalhos de produção e de consumo artísticos. Para tanto, traça uma curiosa analogia entre o gado dinka, analisado por Coote, e uma Ferrari. Assim como as preferências dinka por um gado forte e com longos chifres repousariam em especificações mais práticas que meramente “estéticas”, também as características visuais do automóvel, como pneus largos e múltiplos escapamentos, seriam antes resultado da funcionalidade de sua engenharia, postula Gell. Que completa, com um expressivo exemplo de seu recurso intermitente ao paradigma semiológico: “até mesmo a cor vermelha é antes semiótica do que estética, no que ela indica, aos amantes de carros esportivos, a origem italiana da Ferrari" (I995, p. 24).

Interessa-me menos, entretanto, ressaltar o caráter convencionado do "rosso corsa" automotivo do que a perspicácia gelliana em traçar uma contiguidade entre razões estéticas e práticas presentes num índice - seja este um gado, uma Ferrari ou, para nossos propósitos, um ibiri. Efetivamente, um tal objeto sagrado tem uma finalidade determinada, participa de um sistema ritual cuja visualidade não está destinada ao exercício de deleite desinteressado do belo mas, antes, a serviço de uma certa funcionalidade expressiva de poderes místicos. Sua forma visual é de caráter utilitário: esse objeto é desse modo porque só assim, e não de outro, pode funcionar e fazer funcionar. Sua estética eficaz, calcada em seu poder agentivo, e sua eficácia estética, decorrente da fruição de sua observação, são os dois lados de uma mesma e só moeda.

À semelhança dos porcos e inhames de Hagen, de que nos fala Strathern (2006, passim), e guardadas as devidas proporções e diferenças que os separam, as formas visuais do Ibiri (seu “aparecimento”, para usar do léxico stratherniano) embutem (“eclipsam”) variadas relações sociais, notadamente entre Nanã e o público das galerias de arte (com sua adoração estética quase - ou, nesse caso, por vezes efetivamente religiosa), tendo Mestre Didi por intermediário di(r/l)eto de ligação entre sua plano de existência, o Orun (mundo espiritual) e o nosso, o Aiүé (mundo físico). Se Strathern tem razão ao afirmar que 'coisas' são as formas pelas quais relações aparecem" (I992, p. 249) - entendendo “coisas", nas pistas que Gell fornece em sua exegese 
6 Substância de coloração avermelhada extraída da madeira de Baphia nítida, arbusto originário da África Ocidental popularmente conhecido como sândalo africano. dos conceitos de Strathern, “não [como] coisas-em-si-mesmas isoláveis, mas existindo tão-somente na medida em que veiculam, ou codificam, significado em referência ao código" (Gell, 200Ib, p. 32) - então tais relações, impalpáveis por definição, só se fazem acessíveis por meio de formas materiais de existência. É nessa exata medida que a decomposição da estética - i.e, "um sistema de convenções sociais no qual aparições indicam quais relações entre quais termos” (idem, p. 37) - do Ibiri nos possibilita acessar as complexas relações nele "objetificadas".

Com isso não quero dizer que tal peça de arte seja mera função ou materialização de propósitos e ideias religiosos. Pelo contrário. São múltiplas as potencialidades de abdução de agência que nele se encerram, e a liberdade inovadora de Mestre Didi em sua elaboração corrobora tal assertiva. O ato de circundar as fibras de seu corpo com largas e sequenciadas tiras de couro e de revesti-las com pouco (ou nenhum) pó de osun $^{6}$, por exemplo, manifesta a inventividade artística dos terreiros afro-brasileiros em relação aos ileeshin da tradição Ketu (Thompson, I984). A recriação desse traço estilístico africano, gerando novas modulações de um mesmo conceito, é fartamente intensificada na execução do Ibiri (compará-lo com as imagens o3 e 04). Com efeito, a tradução da tradição por meio de uma linguagem contemporânea das belas-artes é traço fundamental do fazer artístico de Mestre Didi, no qual antigo e novo parecem coadunar-se sem solução de continuidade.

Assim, o encanto da tecnologia empregada por Mestre Didi transforma um instrumento ritual numa poderosa obra de arte. O poder de fascinação que sua obra nos provoca, como acertadamente afirmaria Gell, provém dos processos técnicos que esta personifica (Gell, 2005, p. 45): seu Ibiri é certamente uma tecnologia do encanto. O apuro e requinte impressos à sua confecção, fruto de uma "transubstanciação engenhosa" (idem, p. 53) dos materiais que lhe dão forma e das ideias a eles associados o diferenciam incontestavelmente dos ibiris-padrão. Mas por quê? E em que termos?

Se seguirmos à risca as proposições de Gell, tal diferenciação será dificilmente sublinhada (ou quiçá sequer faça sentido). Em seus termos, entre um ibiri e o Ibiri repousa uma completa sinonímia de status: são ambos objetos artísticos, evocando e encarnando um conjunto de intencionalidades e ideias complexas por intermédio de formas materiais (Gell, I998), tendendo, ambos, a criar uma assimetria entre as pessoas ao colocá-las numa relação igualmente assimétrica com as coisas (Gell, 2005). 
Estar diante de um ou de outro equivaleria, na mesma medida, a encontrar-se com uma pessoa, uma materialidade que incita uma transferência esquemática entre os processos de sua elaboração e a produção de relações sociais por ela mediadas, ocorram elas num terreiro, em que um ibiri indicia, aos olhos dos crentes (seus receptores) uma agência direta de Nanã (seu protótipo), ou num museu, no qual o Ibiri indicia a agência de Mestre Didi (seu artista) aos olhos dos curadores, críticos de arte e público frequentador (seus receptores).

$\mathrm{Na}$ formulação gelliana, entre produções de objetos artísticos (ou, mais propriamente, de "índices") e de relações sociais, residiria uma homologia indeclinável: relações sociais são emergentes dos processos técnicos que as constituem; são características da base técnica sobre a qual a sociedade repousa. Sua proposta de uma teoria antropológica da arte, ao postular que "qualquer coisa poderia ser tratada como objeto de arte do ponto de vista antropológico" (I998, p. 7), é certamente instigante, sobretudo ao pôr fim a um velho clichê antropológico, um tanto etnocentrado, que definiria como casuística a denominação de “arte” à produção material de grupos humanos em cujas línguas tal termo sequer existe. Sua abordagem, “preocupada com o papel prático de mediação que desempenham os objetos de arte no processo social, e não com a interpretação dos objetos 'como se' eles fossem textos” (idem, p. 6), contudo, deixa flagrantemente escapar a especificidade que as obras de arte possuem em nosso mundo.

Ao descartar o papel dos circuitos de arte (seus críticos, museus, curadores etc.), Gell nos brinda com uma excelente teoria de agência do objeto, mas não dá conta de explicar como alguns destes, e não outros, são tratados propriamente como arte. Um ibiri e o Ibiri, de fato, parecem indistinguíveis nos seus termos - embora saibamos que somente este, e não aquele, possui as credencias de circulação em grandes galerias e leilões de arte, a custo inclusive de elevadas cifras.

Diante desse impasse, talvez seja o caso de revisitarmos certa tradição de análise antropológica, com base em M. Mauss, centrada no caráter inerentemente social dos processos que fazem com que algo seja considerado aquilo que é - a mesma que Gell afirma invocar (I998, p. 9), embora, ao que tudo indica, apenas parcialmente. Tratase de levar a sério o ensinamento de que, nas relações sociais, uma "coisa” nunca é: ela sempre é algo. Os objetos de arte não fogem a essa regra. Cito-o: “os fenômenos estéticos formam uma das partes da atividade humana social e não simplesmente in- 
7 É preciso, entretanto, sublinhar que tal recusa é muito menos categórica nos seus textos iniciais sobre o objeto artístico (1995; 2001; 2005), se radicalizando em Art and Agency (1988), seu mais conhecido (e inacabado) livro sobre o tema, lançado postumamente. dividual: uma coisa é bela, um ato é belo, um verso é belo, desde que seja reconhecido como belo pela maior parte das pessoas de gosto. É o que se chama a gramática da arte. Todos os fenômenos estéticos são, em alguma medida, fenômenos sociais” (Mauss, I993, p. 93. O grifo é meu.).

A recusa de Gell7 ao paradigma "institucional" da arte, excessivamente preocupado com os processos de consagração e "efeito de rotulagem reservado ao artworld" (Bourdieu, 20II, p. 28I), é certamente efetiva como fator de contraste à sua ênfase na capacidade agentiva dos objetos artísticos. Seu problema reside, entretanto, em "jogar o bebê junto com a água da bacia”, a dizer, na perda das contribuições que tal abordagem poderia fornecer à sua compreensão antropológica das obras de arte. Podemos dizer o mesmo a respeito de sua postura crítica (contundente na teoria, intermitente na prática) à abordagem de matriz "interpretativa”.

No caso de nosso Ibiri, implica considerar a proposição metodológica de uma “crítica inferencial”, como proposta por M. Baxandall, reveladora do mútuo reforço que conceitos e objetos realizam entre si na análise de arte. Ou, de modo mais preciso, de como "o conceito aprofunda a percepção do objeto e o objeto aprofunda a referência da palavra” (Baxandall, 2006, p. 72), realçando o caráter dêitico e performativo da descrição (que é já explicação, e vice-versa). Descrever as partes visuais que compõem o Ibiri, seus materiais, o modo como estes são articulados no conjunto escultórico, assim como suas relações com os atributos cosmologicamente designados a Nanã, é parte fundamental de sua própria explicação. Acredito, pois, à revelia de Gell, que uma leitura semiótica dos objetos artísticos, desde que lapidada dos excessos interpretativos e calcada no terreno etnográfico, seja sim igualmente tarefa de análise antropológica, o que permite, inclusive, uma compreensão mais aprofundada da capacidade de agenciamento desses objetos na trama das relações sociais em que se encontram subsumidos.

Vejamos o caso do Ibiri: sua composição, característica do fazer artístico profundamente ancorado nas tradições religiosas afro-baianas de Mestre Didi, na qual forma e conteúdo se coadunam de maneira indissociável, é parte indeclinável de sua própria eficácia estética. Ao trançar fibras de palmeira e circundá-las com tiras de couro para dar forma a seu Ibiri, o artista-sacerdote, diferentemente do que uma interpretação genérica (e apressada) poderia postular, não dá uma forma 'cultural', por meio de seu 
trabalho, a recursos retirados da 'natureza'. Ele antes maneja materiais que já são em si 'naturalmente' sagrados, dotados de um axé que lhes é imanente. Seu ato não executa uma transubstanciação desses elementos; mais propriamente, realiza sua consubstanciação num novo corpo, em cujo feitio se conserva a memória do que foram, de modo que a separação entre os domínios da Natureza e da Cultura (essa dicotomia obsessiva do Ocidente "moderno"), pensados como ontologias pretensamente fechadas e inteiriças, parece, destarte, fazer pouco sentido no "tecido inteiriço das naturezas-culturas" (Latour, 2000, p. I2) que fundamenta a cosmovisão dos terreiros.

Nesse sentido, os elementos que conformam o Ibiri, na medida em que carregam o axé de Nanã, são eles mesmos fractais deste orixá, na conotação que Gell confere ao termo: "uma figura que possui a propriedade de auto-similaridade em diferentes escalas de magnificação/minimização” (I998, p. I37), do que se deriva, a fortiori, e em consonância com a afirmação gelliana de que “imagens de algo (um protótipo) são partes desse algo (como objetos distribuídos)" (idem, p. 223), a consideração de que parte da própria personitude de Nanã está imiscuída nos Ibiris.

Mas se os Ibiris, sejam os de Mestre Didi ou não, são uma parte de Nanã e, como vimos, podem ser considerados concomitantemente objetos de arte $e$ artefatos (sobretudo se levarmos a sério a proposição gelliana de indiscernibilidade teórica entre um termo e outro), voltamos então à indagação inicial: como, e em que medida, se pode diferenciá-los? Aos olhos do público cultivado de museus, arriscaria dizer que a resposta mais provável tenderia à desqualificação do ibiri como objeto propriamente de arte frente à riqueza de detalhes e apuro estilístico (de fato inegáveis) do Ibiri de Mestre Didi. Aos olhos de um adepto das religiões afro-brasileiras, a resposta provavelmente repousaria na desqualificação do Ibiri como objeto propriamente religioso frente aos minuciosos e elaborados ritos de sacralização (de fato incontornáveis) pelos quais deve passar um ibiri. O impasse é simétrico e calcado numa suposta falta comum de intencionalidade: num lado, artística; noutro, religiosa ${ }^{8}$.

Entretanto, a resposta mais equilibrada, ainda que potencialmente frustrante, talvez seja: depende de onde eles se encontrem. O Ibiri, feito-para-ser-exposto, uma vez consagrado num terreiro, também poderia ser nele dançado; especularmente, um ibiri, feito-para-ser-dançado, uma vez consagrado pelos circuitos de arte, tam-

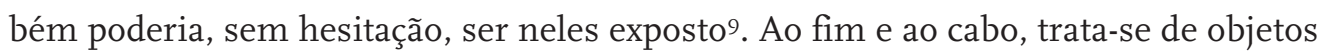

8 Ou, se considerarmos procedente a provocação de Gell de que "na medida em que almas modernas possuam religião, essa religião é a religião da arte" (Gell, 2005, p. 43), então faltaria uma intencionalidade tão-somente "religiosa" a ambos.

9 A rede de caça zande à mostra na exposição Art/Artifact, no Center for African Art (Nova

York, 1988), sobre a qual Gell (2001) dedica uma instigante análise, não me deixa mentir. 
concomitantemente "sagrados" e "profanos" (ou, melhor dizendo, situados entre estes dois domínios): sua diferença, cambiante sob a perspectiva de onde se os observa, é de grau, não de gênero.

\section{Reflexões finais: encruzilhando fronteiras}

O caso dos Ibiris, como pudemos ver, a transitividade entre museus e terreiros é de mão dupla. Nosso estudo desses objetos não poderia escapar da hibridização que lhes é característica, transitando igualmente outros dois campos: os da Antropologia e da Arte.

A perspectiva reticular da análise de Gell, integrando índices, agentes, pacientes, artistas, protótipos e estilos num mesmo nexo artístico, ajudou-nos sobretudo a demonstrar, por meio da escultura de Mestre Didi, a enorme permeabilidade das fronteiras destas áreas. Ao sublinhar que compete à antropologia mais do que decifrar convenções/códigos e que os objetos são mais do que meras metáforas simbólicas de seus contextos, os escritos de Gell se tornaram referência inescapável aos estudos de antropologia da arte. Sua assertiva de que "objetos de arte são caracteristicamente 'difíceis'. Difíceis de fazer, de 'pensar', de 'realizar'. Eles fascinam, compelem e capturam, tão como aprazem o espectador. Sua peculiaridade, intransigência e estranheza é o fator chave de sua eficácia como instrumentos sociais.” (Gell, I998, p. 23) Continua de enorme valia e atualidade.

É claro que a fruição de uma obra de arte, o prazer de sua contemplação, independe das explicações prévias de seus significados simbólicos ou de sua intermediação no emaranhado das relações sociais de sua produção. Mas não é disso que se ocupa uma abordagem antropológica da arte. Com efeito, um posicionamento esteado no juízo de gosto é tão subjetivo quanto de pouca rentabilidade a propósitos analíticos. Como afirma o antropólogo britânico Peter Gow, “Antropologia compara e contrasta, mas não julga. Ela abjura, espero, discriminação no sentido de julgamentos estéticos sobre as culturas estudadas, mesmo quando estes lhes possam ser favoráveis”. (apud Ingold, op. cit., p.220).

Nesse aspecto, o convite de Gell a dirigirmos nossa atenção às capacidades de abdução da agência dos objetos artísticos é, incontestavelmente, instigante. No caso do Ibiri de Mestre Didi, esta perspectiva pareceu-me indispensável no controle dos 
possíveis exageros interpretativistas, tão comuns aos estudos que lhe foram até então dedicados e que tendem a reduzi-los a "instrumentos de comunicação que, através de sua forma significante, contribuem para manifestar e transmitir a complexa trama simbólica." (Santos, I996, n.p.). Entretanto, 'simbolismo' não necessariamente tem uma função substituinte: um símbolo não é só algo que metaforiza uma realidade, falando dela de outro modo. Ele é também uma realidade em si, que fala sobre algo sem, contudo, com ele confundir-se. Para usar as palavras de Lévi-Strauss,

Ao colocar a natureza simbólica de seu objeto, a antropologia social não pretende nem por isso afastar-se das realia. Como poderia fazê-lo uma vez que a arte, onde tudo é signo, utiliza veículos materiais? Não se podem estudar os deuses e ignorar suas imagens; os ritos, sem analisar os objetos e as substâncias que o oficiante fabrica e manipula; regras sociais, independentemente de coisas que lhes correspondem. A antropologia social não se isola em uma parte do domínio da etnologia; não separa cultura material e cultura espiritual. Na perspectiva que lhe é própria - e que nos será necessário situar - ela lhes atribui o mesmo interesse. Os homens se comunicam por meio de símbolos e signos; para a antropologia, que é uma conversa do homem com o homem, tudo é símbolo e signo que se coloca como intermediários entre dois sujeitos (Lévi-Strauss, 2008, p. 20).

Isso nos incita a perceber que a recusa (seletiva) de Gell aos aportes de uma análise de inspiração iconográfica e/ou institucional acabou por empobrecer sua proposta de uma nova antropologia da arte, convertendo-a num modelo programático um tanto enrijecido, mais do que numa perspectiva de fato abrangente de análise, sobretudo por não atentar-se aos mecanismos de consagração e desvalorização de objetos artísticos no mundo de museus, leilões e curadores em que vivemos, como tentamos demonstrar por meio da dupla face de Janus que o Ibiri, a um só tempo arte e artefato, encerra. Em outras palavras, a questão aqui problematizada é, para usar os termos de N. Goodman (apud Ingold, op. cit., p. 228), “não o que é arte mas quando é arte”.

Acredito que a leitura e significação das obras de arte se tornam mais inteligíveis na exata medida em que são inseridas nas contextualizações social e culturalmente mais amplas. Destarte, numa abordagem mais formalista, preocupada com disposições e cânones estéticos, relações entre elementos estilísticos, harmonias e composições pictóricas; e uma visão mais historicista, atenta sobretudo à investigação dos conteúdos intrínsecos e latentes da obra de arte e à sua contextualização, um tanto imediata, no tempo histórico-social de sua produção e produtor, parece-me mais seguro analisá-las 
por meio do estabelecimento de "relações entre o objeto e suas circunstâncias" (Baxandall, 2006), superando a inocuidade modelar dessa dicotomia.

A forma importa, revela, encarna, autoriza, mas pouco diz se prescinde de uma análise do contexto que a condiciona e possibilita sua própria experiência estética e capacidade agentiva. Indo além: a forma é conteúdo (e vice-versa), de onde se extrai que a separação dos dois domínios atenda muito mais a funções didáticas e sejam fruto, talvez, mais de disputas de fronteira entre distintos campos do conhecimento do que domínios fenomenologicamente separados.

\section{Referências}

BAXANDALL, M. Padrões de intenção - a explicação histórica dos quadros. São Paulo: Companhia das Letras, 2006.

BOURDIEU, P. O Poder Simbólico. Rio de Janeiro: Bertrand Brasil, 20II.

CASTRO, C. (org.). Evolucionismo: Textos de Morgan, Tylor e Frazer. Rio de Janeiro: Jorge Zahar Ed., 2005 .

CLIFFORD, J. The predicament of culture. Cambridge: Harvard University Press, I988.

COOTE, J. "Marvels of everyday vision": the anthropology of aesthetics and the Cattle-Keeping Nilotes". In. J. Coote \& A.Shelton. Anthropology, art, aesthetics. Oxford: Clarendon Press, p. 245-275, 1992.

DUFRENE, T. "Art contemporain et anthropologie". In: Anais do XXXII Colóquio CBHA, pp. Io9I36, 2012.

GELL, A. “On Coote's 'Marvels of Everyday Vision””. In: J. F. Weiner (ed.), Too Many Meanings: A Critique of the Anthropology of Aesthetics, special issue, Social nalysis, no. 38, p. I8-3I, I995.

GELL, A. Art and agency. Oxford: Clarendon Press,1998.

GELL, A. "A rede de Vogel: armadilhas como obras de arte e obras de arte como armadilhas", In: Arte e Ensaios. n. 8, p. I74-I9I, 200 I.

GELL, A. 20orb. "Strathernograms". In. The Art of Anthropology (essays and diagrams). London: The Athlone Press, p. 215-232, 200I.

GELL, A. "A tecnologia do encanto e o encanto da tecnologia". In: Concinnitas. .v. I, n. 8, p. 4I-63, 2005[I992].

INGOLD, T. (ed). Key Debates in Anthropology. London, Routledge. (Cap. "Aesthetics is a cross-cultural category", I994. p. 249-294.

LATOUR, B. Jamais fomos modernos. São Paulo: Ed. 34, 2000. 
LAYTON, R. H. "Art and agency: a reassessment". Journal of the Royal Anthropological Institute, 9 (3). p. 447-463, 2003.

LEVI-STRAUSS, C. A via das máscaras. Lisboa: Editorial Presença, I979 [I975].

LEVI-STRAUSS, C. O campo da Antropologia. In: Antropologia estrutural dois. São Paulo: Cosac Naify, 2008.

MAUSS, M. Manual de etnografia. Lisboa: Dom Quixote, I993.

MORPHY, H. "The Anthropology of Art”. In: T.Ingold (Ed). Companion Encyclopaedia of Anthropology. London \& New York: Routledge p. 648-685, I994.

PRANDI, R. Mitologia dos orixás. São Paulo: Companhia das Letras, 200 I.

SAHLINS, M. 2004. Esperando Foucault, ainda. São Paulo: Cosac \& Naify, 2004.

SANTOS, J. E. dos. Os Nàgô e a morte: Pàde, Àsèsè e o culto Ègun na Bahia. Petrópolis: Editora Vozes, I979.

SANTOS, J. E. dos. "Bimestre Didi: tradição e contemporaneidade". In: AGUILAR, Nelson (org.). Catálogo da XXIII Bienal de São Paulo, Salas Especiais. São Paulo: Fundação Bienal de São Paulo,1996. p. 264-295.

SANTOS, J. E. dos. Ancestralidade africana no Brasil: Mestre Didi, 80 anos. Salvador: SECNEB, I997.

SANTOS, J. E. dos. (org.). Autos Coreográficos: Mestre Didi, 90 anos. Salvador: Corrupio, 2007.

SCHWARCZ, L. M. \& PEDROSA, A. (orgs.). Histórias Mestiças - catálogo da exposição. Rio de Janeiro: Cobogó; São Paulo: Instituto Tomie Ohtake, 2015.

STOCKING Jr., G. (ed.). Objects and Others (essays on museums and material culture). Madison: The University of Winscosin Press, I985.

STOCKING Jr., G. (ed.). Victorian Anthropology. New York: The Free Press, I987.

STRATHERN, M. “The decomposition of an event”. In: Cultural Anthropology, Vol. 7, N. 2, p. 244254, I992.

STRATHERN, M. I992. O Gênero da Dádiva. Problemas com as mulheres e problemas com a sociedade na Melanésia. Campinas: Editora da Unicamp, 2006.

THOMPSON, R. F. Flash of the Spirit: African \& Afro-American Art \& Philosophy. Random House, I984. WAGNER, R. A invenção da cultura. São Paulo: Cosac Naify, 20 Io. 